\title{
THE REGIONAL THE IMPACT OF CHANGES ON THE COMPETITIVENESS OF THE EGYPTIAN ORANGE IN THE MOST IMPORTANT FOREIGN MARKETS
}

\author{
AHMED FOUAD, NASSER HAMMAM and SALAH ELWAN
}

Agric. Economic Research Institute, ARC, Giza

(Manuscript received 18 February 2016)

\begin{abstract}
gyptian Orange is considered one of the most important Agricultural crop either for local consumption or Exporting, The Exports value of orange represent $45.6 \%$ from the total fruit exports during the period (2012-2014). The Egyptian Orange Exports in the main foreign markets Saudia Arabia, Russia and Ukraine reached about $21 \%, 19.2 \%, 10.3 \%$ and $8.3 \%$ respectively during the same period. The object of the study is to recognize the competitiveness of Egyptian Orange in some foreign markets. It was obvious that Egypt has relative price (RP) advantage in Saudia market which it reached about 1, 0.78, 0.91, 0.66 for Egypt, Spain, United states and Chili respectively during the period (2005-2009), Market penetration ratio (MPR) reached about $0.60,0.28,0.10$ for Egypt, South Africa and Lebanon during the period (2005-2009). In Russian market the relative production for China, Spain and Egypt reached about 0.90, 0.43, 0.38 respectively, Further, Egypt has an advantage in Ukrainian market which reached about 16.84, 2.96 and 2.09 for Egypt, Greece and Argentina during the same period Seasonal window has been studied, the seasonal index for Saudi Arabian and Russian markets reached about 155,154 in February during (2012-2014). The research ended to some recommendations such as: It is necessary to study the markets of importing Countries and must make Agricultural contracts with Orange producers.
\end{abstract}




\section{أثر التغيرات الإقليمية على تنافسية البرتقال المصرى فى أهم أسواقه الخارجية}

أحمد فؤاد ، ناصر همام ، صلاح علوان

\section{معهذ بحوث الأقتصاد الزراعي - مركز البحوث الزراعية \\ الملخص}

يعتبر البرتقال المصرى من اهم المحاصيل الزراعية ذات الاهمية

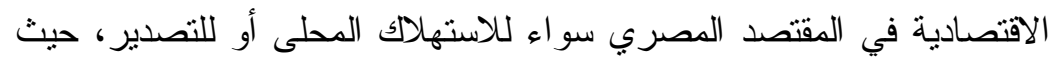

يمثل نحو 93\% من اجمالي قيمة صادرات الموالح البالغة نحو 499.5 مليون دو لار أمريكي وحو الي 45.6\% من اجمالي قيمة صادر ات الفاكهة البالغة نحو 1016.6 مليون دولار أمريكي كمتوسط للفترة (2014-2012)، إلا إنه

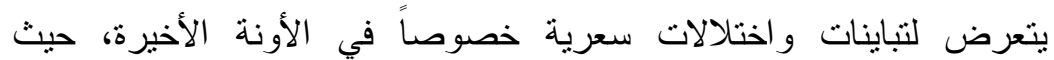
انخفضت قيمة صادر اته من حو الي 494.7 مليون دو لار أمريكي عام 2009 إلي حوالي 456.4 مليون دولار أمريكي عام 2012، ويتمنل الهدف الرئسي للبحث في التعرف علي القدرة التتافسية للبرتقال المصري وكيفية تتمية صادر اته إلي السوق العالمي، وكانت أهم النتائج تذبذب نسبة تغطية الصادرات للواردات خلال فترة الدراسة، وأن أهم الاسواق الخارجية المستوردة للبرتقال المصرى من حيث الاهية النسبية هى كل من السعودية، روسيا الاتحادية، اوكرانبا، الامارات العربية المتحدة، حيث بلغت الاهمية النسبية لمتوسط الهمئه الصادرات المصرية لهذه الاسواق حوالي 21.0\%، 19.2\%، 10.3\%، \%8.3، على التزتيب من منوسط اجمالى صادرات البرتقال المصري البالغة

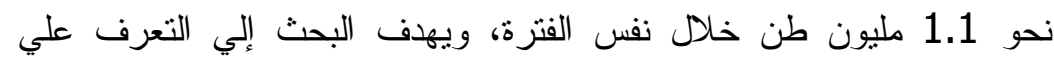
تتافسية البرتقال المصري في أهم اسواقه العالمية، وقد نم التركيز علي أهم الأسواق وهي السعودي و الروسي و الأوكراني، حيث بلغت نسبة الصادرات لهذه الأسواق نحو 21\%، 19.2\%، 10.3\% كمنوسط للفترة (20122014)، وقد بلغت كمية صادرات البرتقال المصري أقصاه بنحو 1042.3

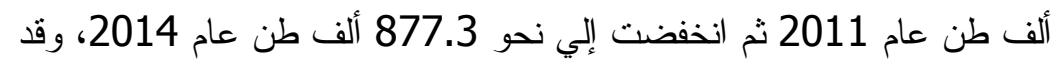
تبين أن مصر لها مبزة نسبية سعرية في السوق السعودي عن كل من أسبانيا، الولايات المتحدة الإمريكية، شيلي حيث بلغت النسبة السعرية نحو

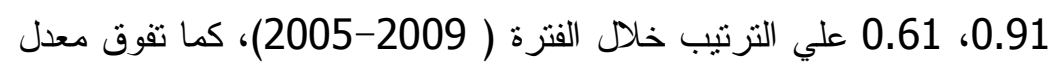

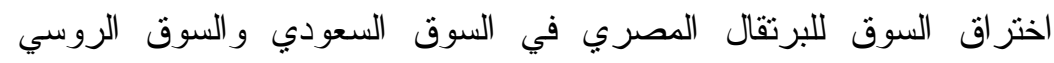
و السوق الأوكر اني لغالبية الدول المنافسة خلال فترتي الدراسة، كذللك تبين أن لمصر ميزة نسبية ظاهرة في الأسواق الثلاث حيث تراوحت بين حد أعلي 
بنحو 34.8 في السوق الروسي خلا فترة الدراسة الثانية وحد ادني بلغ نحو

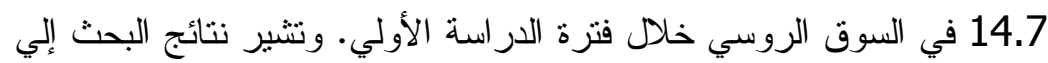

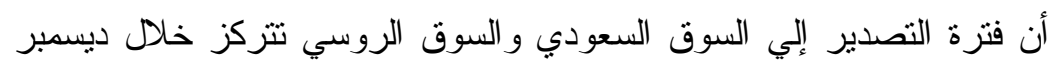

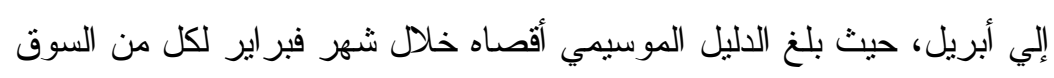

السعودي والروسي وذللك بنحو 155، 145 علي الترتيب خلايل الفترة

.(2014-2012)

\section{مقدمة}

يعتمد المقتصد المصري علي توفير احتياجاته من النقد الأجنبي علي تتمية صادراته من السلع

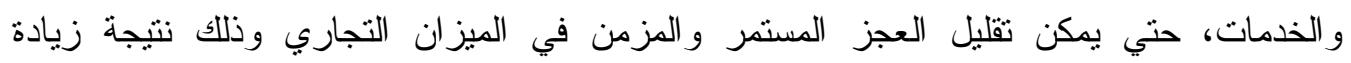

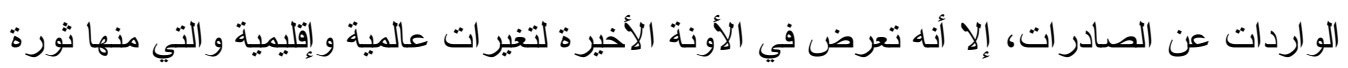

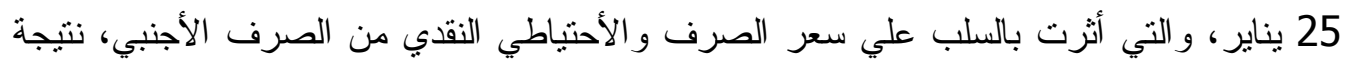
زيادة الواردات لتلبية احتياجات الطلب المحلي وتعطل طاقات التبل الإنتاج عن العمل.

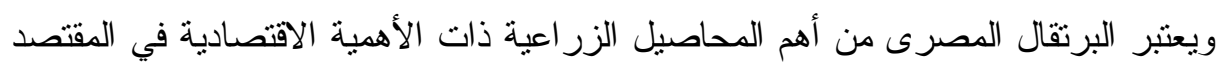

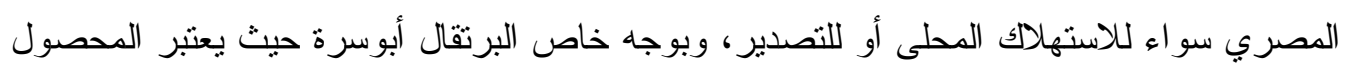

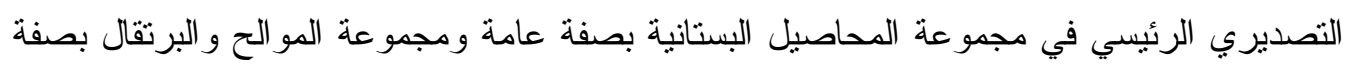
خاصة حيث يمنل انتاجة حوالي 51.6 \% من اجمالي انتاج اصناف البرتقال البالغة نحو 3.1

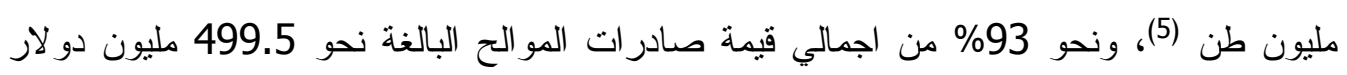

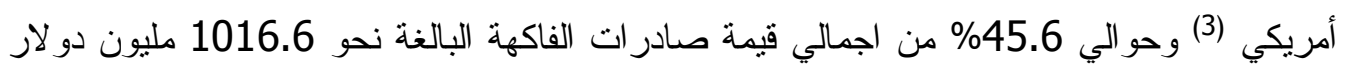
أمريكي كمتوسط للفترة (2014-2012) (3)، بالاضافة الى مميز اتة الغذائية والاستهلاكية التى تزيد

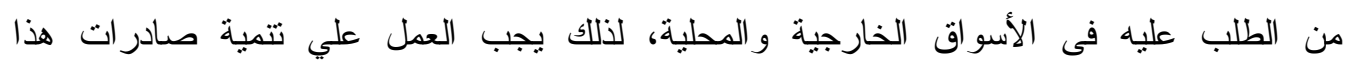
المحصول لما يسهم به في تقليل العز المزمن و المستمر في الميزان التجاري وتوفير النقد الأجنبي.

\section{مشكلة البحث}

تشير الشو اهد إلي تعرض البرتقال المصري لحدوث تباينات واختلالات سعرية خاصة في الأونة الأخيرة، حيث انخفضت قيمة صادر اته من حو الي 494.7 مليون دو لار أمريكي عام 2009

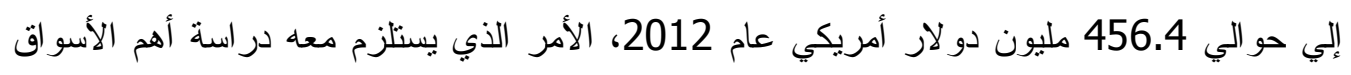
الخارجية المستوردة للبرتقال المصري للوقوف علي أسباب تلاك الاختلالات وكيفية تلافيها.

\section{هدف البحث}

يتمثل الهدف الرئسي للبحث في التعرف علي القدرة التنافسية للبرتقال المصري وكيفية تتمية صادر اته إلي السوق العالمي وذللك من خلال مجموعة أهداف فرعية هي:

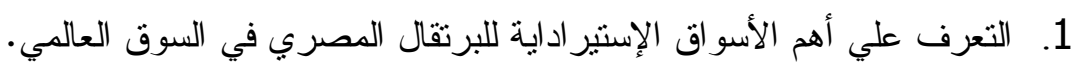
2. در داسة الميزة التتافسية للبرتقال المصري في أهم أسو اقة الخارجية. 3. در اسة أثز التقلبات الإقليمية علي صادرات البرتقال المصري في أهم أسو اقه الخارجية.

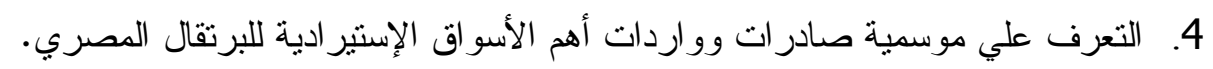




\section{الطريقة البحثية ومصادر البياتات}

لقد تم استخدام كل من الطريقة الكمية والوصفية كالانحدار البسيط والمتعدد ومعدلات النمو

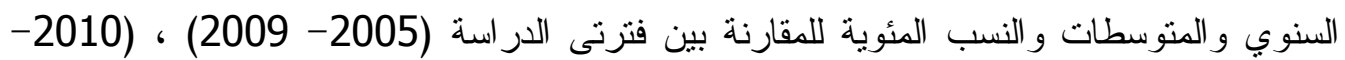

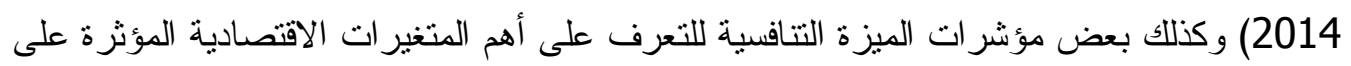


البيانات الثانوية في تحقيق هدفه كذلك الكتب و الرسائل و المر اجع العلمية الأخري، هذا بالأضافة إلي الي الئي

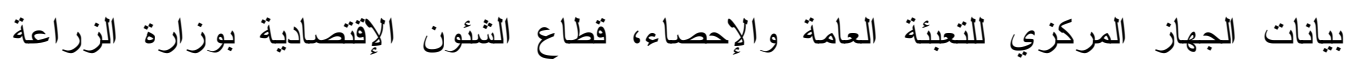
و استصلاح الأر اضي، قاعدة بيانات الأمم المتحدة للتجارة.

\section{الإطار النظري والتحليلي للبحث}

فيما يلى المؤشرات الاقتصادية للتنافسية التي تم استخدامها:

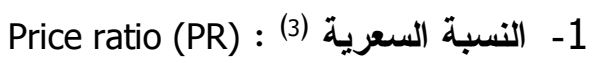

اى النسبة بين متوسط اسعار التصدير لاهم الدول المنافسة الى منوسط سعر التصدير

Paj=Pc/Pe المصري.

Paj = . Paj= النسبة بين منوسط اسعار الدول المنافسة الى متوسط سعر الدولة المصدرة Paj $\mathrm{Pc} / \mathrm{Pe}$ متوسط اسعار اهم الدول المنافسة. PC سعر تصدير السلعة من الدول المصدرة. Pe

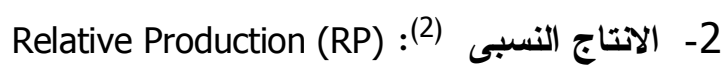

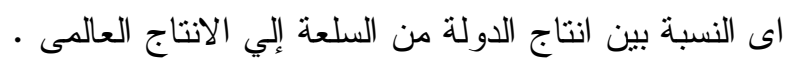

$$
\begin{gathered}
Q_{A j}=Q_{e} / Q_{w} \\
\text { الدالة }=Q_{e} \\
\text { الانتاج العالمى = }=Q_{w}
\end{gathered}
$$

3- معدل اختراق الاسواق (1): Market penetration rate (MPR)

وهو عبارة عن النسبة بين صادرات الدولة من السلعة واستهلاكها الظاهرى فى الدولة

$$
\text { المستوردة. }
$$

$$
M P R_{i j}=E X_{i j} J /\left(Q_{i j}+M_{i j}-X_{i j}\right)
$$

$$
\begin{aligned}
&=X_{i j} \\
& \text { كمية صادر ات الدولة المصدرة. }=Q_{i j} \\
& \text { النتاج الدولة المستوردة }=M_{i j} \\
&=X_{i j}
\end{aligned}
$$

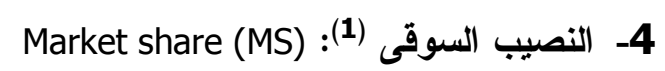

وهو عبارة عن النسبة المئوية لكمية صادرات الدولة المصدرة للسلعة من اجمالى واردات الدولة

المسنوردة لتلاك السلعة.

$$
M_{a j}=E^{1}{ }_{a} / I^{1}
$$




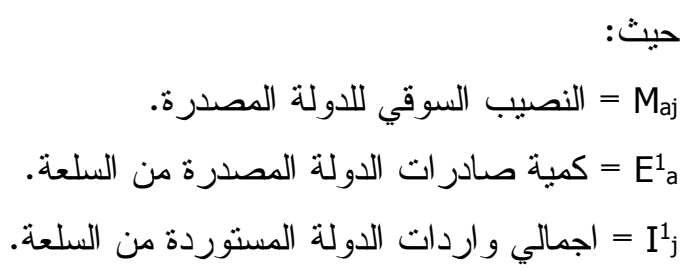

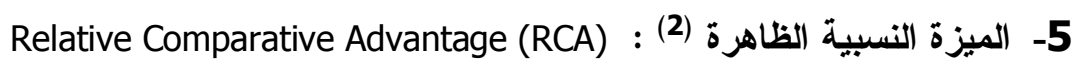

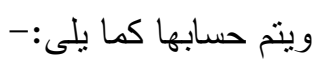

$\operatorname{RCA}_{j}=\left(X_{e}{ }^{1} / X_{e}^{a}\right) \div\left(X_{w}{ }^{1} / X_{w}{ }^{a}\right)$

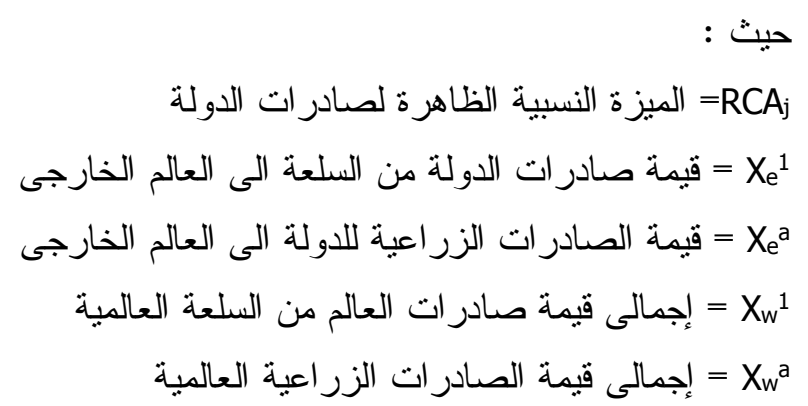

\section{النتائج و المناقشة}

تطور الميزان التجارى المصرى:

نم دراسة الميزان التجارى المصرى خلال الفترة (2014-2000) لمعرفة ما طرأ عليه

من تغيرات و الوقوف على نسبة تغطية الصادرات للواردات حيث يتضح من الجدول رقم (1) أن سعر الدولار مقابل الجنية المصرى قد ارتفع من 3.48 عام 2000 الى 6.21 عام 2004 ائ تلى انخفض الجنية المصرى مقابل الدولار الامريكى ، ثم بدأ السعر فى الانخفاض من 6.21 عام 6.21 عام 2004 ليبلغ نحو 5.97 عام 2011، وارتفع سعر الدولار الامريكى بشكل ملحوظ فى أعقاب لابل

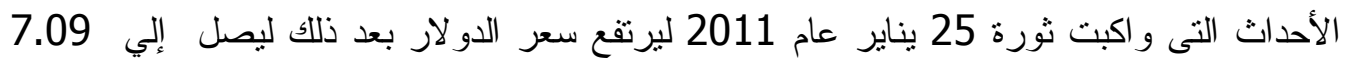

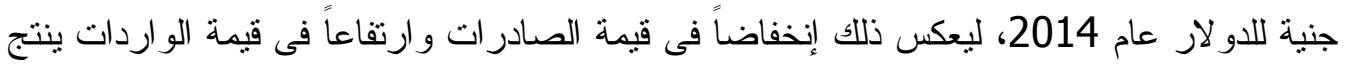

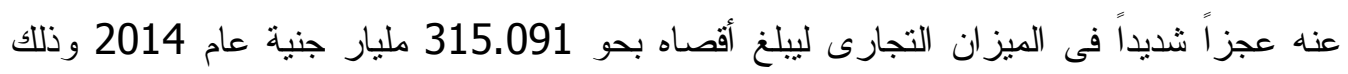

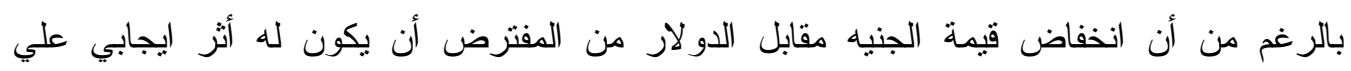

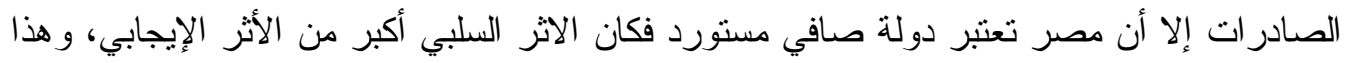
ما يفسر زيادة العجز في الميزان التجاري. ويتضح ذلك من بيانات نفس الجدول إرتفاع قيمة الصادرات من نحو 16.351 مليار جنية عام 2000 ليبلغ حو الي 189.733 مليار جنية عام 2014 بر غم إنخفاضه عام 2012 فى أعقاب ثورة

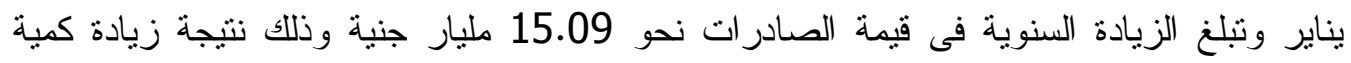

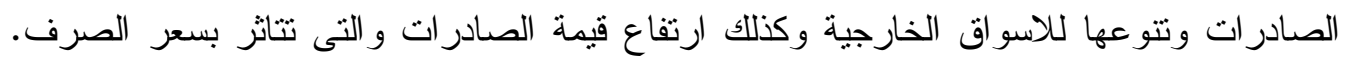

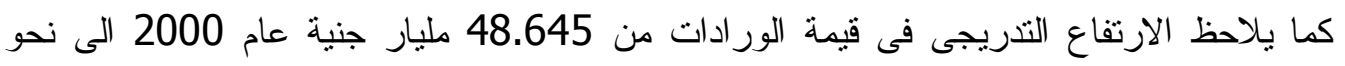

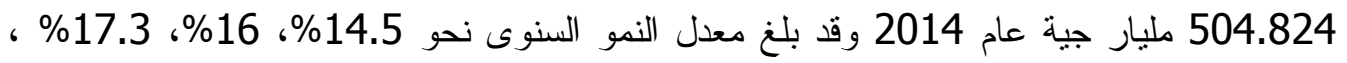


15.5\% لكل من قيمة الصادرات، قيمة الواردات ، الميزان التجارى، حجم التجارة على التزتيب خلال الفترة (2014-2000). جدول رقم (1): تطور سعر الصرف و الميزان التجاري الكلي المصري ونسبة تغطية الصادرات للواردات خلال الفترة (2014-2000)

(القيمة بالمليار جنيه)

\begin{tabular}{|c|c|c|c|c|c|c|}
\hline لنغطية & حجم التجارة & الميزان التجارى & قيمه الو اردات & قيمه الصادر ات & الصرف & السنة \\
\hline 34 & 64.996 & -32.294 & 48.645 & 16.351 & 3.48 & 2000 \\
\hline 33 & 67.150 & -34.168 & 50.659 & 16.491 & 3.98 & 2001 \\
\hline 37 & 77.627 & -35.337 & 56.482 & 21.145 & 4.52 & 2002 \\
\hline 57 & 101.895 & -28.271 & 65.083 & 36.812 & 5.97 & 2003 \\
\hline 60 & 127.394 & -32.038 & 79.716 & 47.678 & 6.21 & 2004 \\
\hline 54 & 176.313 & -53.063 & 114.688 & 61.625 & 5.79 & 2005 \\
\hline 67 & 197.236 & -39.508 & 118.372 & 78.864 & 5.75 & 2006 \\
\hline 60 & 243.842 & -61.330 & 152.586 & 91.256 & 5.64 & 2007 \\
\hline 50 & 430.831 & -144.617 & 287.724 & 143.107 & 5.45 & 2008 \\
\hline 54 & 384.554 & -115.382 & 249.968 & 134.586 & 5.56 & 2009 \\
\hline 52 & 455.211 & -145.511 & 300.361 & 154.850 & 5.66 & 2010 \\
\hline 51 & 559.796 & -183.094 & 371.445 & 188.351 & 5.97 & 2011 \\
\hline 41 & 612.211 & -255.187 & 433.699 & 178.512 & 6.1 & 2012 \\
\hline 43 & 653.712 & -258.284 & 455.998 & 197.714 & 6.88 & 2013 \\
\hline 38 & 694.557 & -315.091 & 504.824 & 189.733 & 7.09 & 2014 \\
\hline 48.7 & 323.16 & -115.54 & 219.35 & 103.8 & 5.6 & المتوسط \\
\hline 0.2 & $* 50.23$ & $*-20.05$ & $* 35.14$ & $* 15.091$ & $* 0.2$ & مقدار التغير السنوي \\
\hline 0.236 & 15.849 & -8.410 & 13.130 & 18.002 & 4.715 & قيمة ت المحسوبة \\
\hline 0.06 & 251.1 & 70.7 & 172.4 & 324.1 & 22.2 & قيمة ف المحسوبة \\
\hline 0.01 & 0.95 & 0.84 & 0.93 & 0.96 & 0.63 & 2 \\
\hline 0.3 & 15.5 & 17.3 & 16.0 & 14.5 & 3.1 & معدل النمو \\
\hline
\end{tabular}

المصدر : جمعت وحسبت من بيانات الجهاز المركزي للتعبئة العامة والأحصاء، شبكة المعلومات الدولية، الأنترنت.

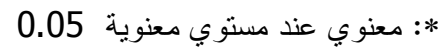
وقد تلاحظ تذبذب نسبة تغطية الصادرات للواردات خلال فترة الدراسة فقد بلغت نحو

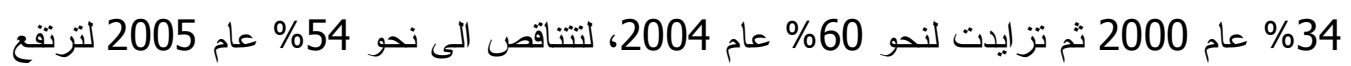

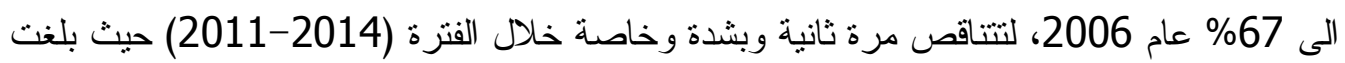
نحو 51\% عام 2011، نحو 38\% عام 2014 لتبلغ أقل نسبة كما هو الحال عام 2000 كما سبق لق 
تطور صادرات البرتقال المصري:-

تشير بيانات الجدول رقم ( 2) إلي أن كمية صادرات البرتقال بلغت في المتوسط حوالي 560.6 الف طن خلال الفترة (2014-2000)، حيث تزايدت تلك الكمية بمعدل تغير سنوي معنوي إحصائيا بلغ نحو 50.8 الف طن ومعدل نمو سنوي قدر بحوالي 9.1\%، وبدراسة أثر التغير ات الإقليمية الحادثة خلال عام 2010 ( ارتفاع سعر الصرف - تعطل طاقات الإنتاج - تغير

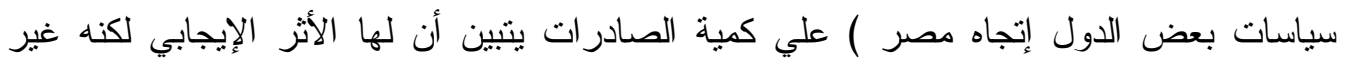

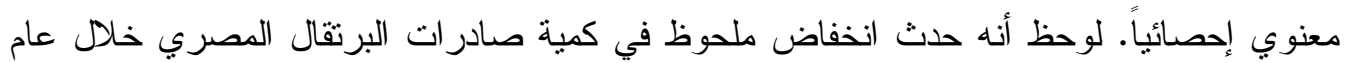
2014 حيث بلغ نحو 877.3 الف طن، بينما ز اد عن المليون طن خلال الفترة ( 2010 - 2013) حيث بلغ أقصاه بنحو 1.3 مليون طن عام 2012.

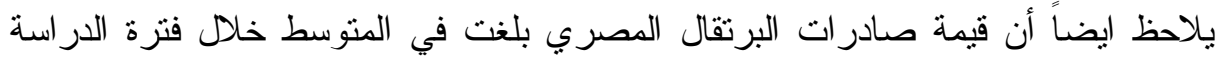

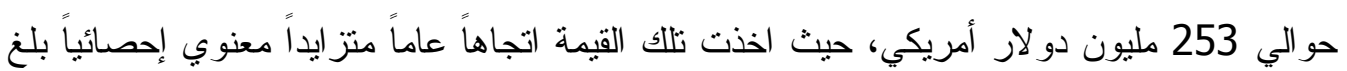

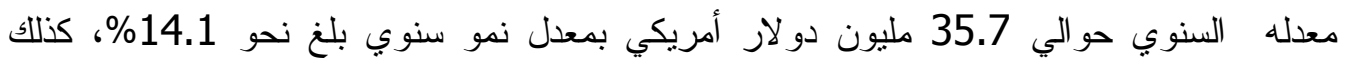
يتضح أن الثقلبات الإقليمية كان لها الأثر الإيجابي علي القيمة لكن لم تثبت معنويته إحصائياً. وفيما يتعلق بالسعر يتضح أنه بلغ في المتوسط حوالي 382.3 دو لار أمريكي للطن خلال نفس الفترة، وقد تز ايد بمعدل تغير سنوي معنوي إحصائياً قدر بحوالي 36.5 دو لار أمريكي للطن

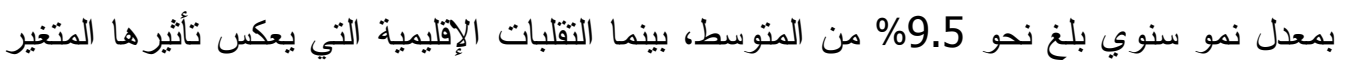
الإنتقالي جاءت بالأثز السلبي علي سعر تصدير البرتقال المصري.

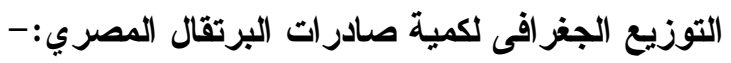
بدر اسة التوزيع الجغر افى للصادرات المصرية من البرتقال خلال منوسط الفترة ( 20102014 ) يتبين من الجدول رقم (3) أن أهم الاسواق الخارجية المستوردة للبرتقال المصرى من حيث الاهمية النسبية هى كل من السعودية، روسيا الاتحادية، اوكرانيا، الامارات العربية المتحدة،

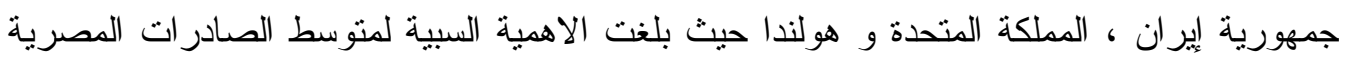

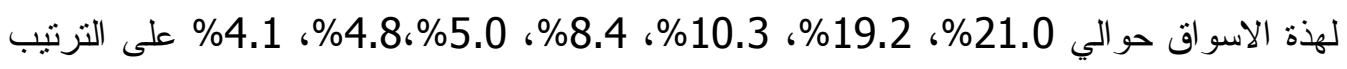
من منوسط اجمالى صادرات البرتقال المصري البالغة نحو 1.1 مليون طن خلال نفس الفترة، أما

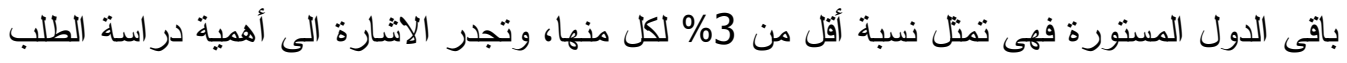

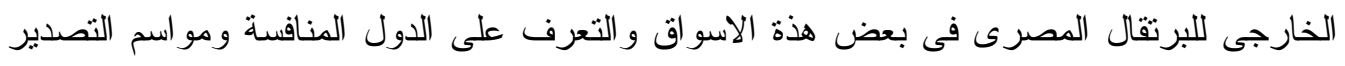

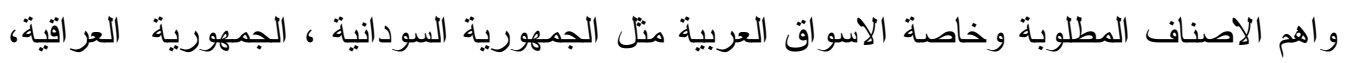
دولة الكويت، عمان و المملكة الاردنبة الهاثمية حيث بلغت الاهمية النسبية لصادرات البرتقال المصرى لها نحو 2.9\%، 2.7\% 2.5\% 2.1، 1.3، على الترنيب كمتوسط خلال نفس الفترة .


طن عام 2010 الى 1322.1 الف طن عام 2012، ثم انخفضت الى 877.3 الف طن عام 2014 بمتوسط بلغ نحو 1050.5 الف طن خلام الفترة (2014-2010) و هذا ما سيتم تقسيرة عند دراسة مؤشر ات النتافسية فى بعض الاسو اق الهامة. 
جدول رقم (2) تطور كمية وقيمة وسعر صادرات البرتقال المصري خلال الفترة (2014-2000) الكمية/ الف طن - القيمة/ مليون دولار أمريكي - السعر / دولار أمريكي للطن

\begin{tabular}{|c|c|c|c|}
\hline سعر التصدير & قيمة الصادر ات & كمية الصادرات & 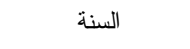 \\
\hline 212.1 & 49.7 & 234.2 & 2000 \\
\hline 196.3 & 50.6 & 257.9 & 2001 \\
\hline 209.4 & 26.5 & 126.7 & 2002 \\
\hline 234.4 & 38.9 & 166.0 & 2003 \\
\hline 299.3 & 66.5 & 222.0 & 2004 \\
\hline 349.9 & 74.9 & 214.2 & 2005 \\
\hline 230.3 & 65.1 & 282.7 & 2006 \\
\hline 362.5 & 99.5 & 274.5 & 2007 \\
\hline 598.2 & 381.6 & 637.9 & 2008 \\
\hline 602.2 & 495.0 & 822.0 & 2009 \\
\hline 598.2 & 490.9 & 820.7 & 2010 \\
\hline 516.1 & 537.9 & 1042.3 & 2011 \\
\hline 343.2 & 453.8 & 1322.1 & 2012 \\
\hline 443.5 & 491.5 & 1108.2 & 2013 \\
\hline 538.7 & 472.6 & 877.3 & 2014 \\
\hline 382.3 & 253.0 & 560.6 & المتوسط \\
\hline $36.5 *$ & $35.7 *$ & $50.8 *$ & معدل التغير السنوي \\
\hline 9.5 & 14.1 & 9.1 & معدل النمو \\
\hline-114.9 & 86.5 & 329.7 & $\mathrm{D} * *$ \\
\hline 9.588 & 25.557 & 31.154 & $\mathrm{~F}$ \\
\hline 0.62 & 0.81 & 0.84 & $R^{2}$ \\
\hline
\end{tabular}

المصدر : جمعت وحسبت من بيانات الجهاز المركزى للتعبئة العامة و الإحصاء ، شبكة المعلومات الدولية ، الانترنت . 0.05 * : نثير إلي المعنوية عند مستوي D** نتير إلي المتغير الإنتقالي الذي يعكس تأثير التغيرات الإقليمية بداية من عام 2010 ( تغير سعر الصرف، تعطل طاقات الإنتاج، تغير في سياسات بعض الدول اتجاه مصر) علي صادرات البرتقال المصري، حيث يأخذ صفر عند عدم وجود الظاهرة، و يأخذ واحد عند وجود الظاهرة. 
جدول رقم (3): التوزيع الجغرافي لكمية وقيمة صادرات البرتقال المصري

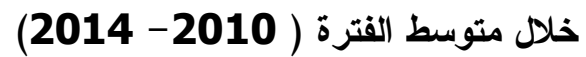

الكمية/ ألف طن - القيمة / مليون جنيه

\begin{tabular}{|c|c|c|c|c|c|}
\hline للقيمة \% & متوسط القيمة & الدول & للكمية \% & متوسط الكمية & الدولة \\
\hline 19.1 & 569.2 & السعودية & 21.0 & 222.7 & السعودية \\
\hline 22.0 & 654.3 & روسيا الأتحاديه & 19.2 & 203.6 & روسيا الأتحاديه \\
\hline 7.2 & 214.7 & اوكر انيا & 10.3 & 109.7 & اوكر انيا \\
\hline 6.4 & 190.6 & الامار ات & 8.4 & 89.1 & الامار ات \\
\hline 5.6 & 167.3 & اير ان & 5.0 & 52.8 & اير ان \\
\hline 4.5 & 133.9 & المملكة المتحدة & 4.8 & 51.3 & المملكة المتحدة \\
\hline 4.3 & 128.8 & هولندا & 4.1 & 43.1 & هولندا \\
\hline 3.0 & 90.3 & السودان & 2.9 & 31.2 & السودان \\
\hline 2.7 & 80.1 & العر اق & 2.7 & 28.9 & العراق \\
\hline 2.5 & 73.5 & الكويت & 2.5 & 26.3 & الكويت \\
\hline 3.0 & 88.5 & بنجلاديش & 2.3 & 24.9 & بنجلاديش \\
\hline 2.0 & 60.5 & عــان & 2.1 & 22.1 & عهـان \\
\hline 2.1 & 63.1 & الهــــند & 1.7 & 18.1 & الهـــــد \\
\hline 1.8 & 53.4 & ليتو انيا & 1.3 & 13.4 & لينو انيا \\
\hline 1.3 & 38.1 & الاردن & 1.3 & 13.3 & الاردن \\
\hline 1.3 & 38.4 & ماليزيا & 1.1 & 11.7 & ماليزيا \\
\hline 0.9 & 27.7 & قطـــر & 0.9 & 9.9 & قطــر \\
\hline 1.2 & 34.6 & فلنلندا & 0.8 & 8.9 & فنلندا \\
\hline 8.98 & 267.3 & اخري & 7.49 & 79.5 & اخري \\
\hline 100.0 & 2974.2 & الاجمالي & 100.0 & 1050.5 & الاجمالي \\
\hline
\end{tabular}

المصدر: جمعت وحسبت من بيانات الجهاز المركزي للتعبئة العامة و الأحصاء، شبكة المعلومات الدولية، الأنترنت.

التوزيع الجغرافى لقيمة صادرات البرتقال المصري:-

يوضح الجدول رقم (3) أن أهم الدول المستوردة للبرتقال المصرى من من حيث قيمة

الصادرات هى روسيا الاتحادية، المملكة العربية السعودية ، جمهورية اوكرانيا، الامارات العربية

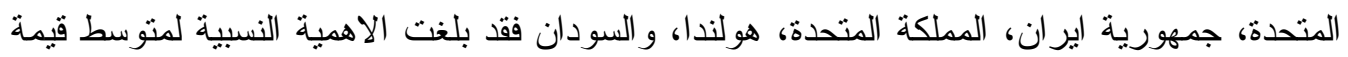

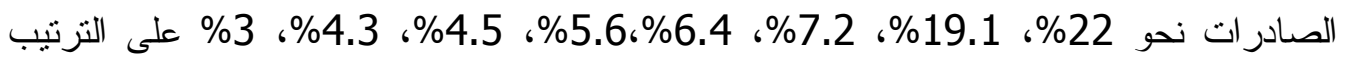


اما باقى الدول فقد أنخفضت الاهمية النسبية لقيمة الصادرات المصرية من البرتقال

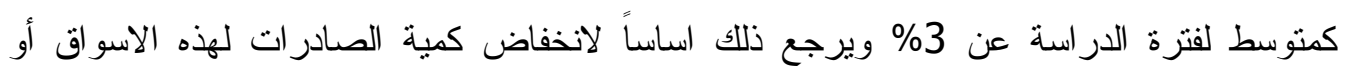
لعو امل اخرى اهمها سعر التصدير وتكاليف الثحن التى يتحملها المستورد.

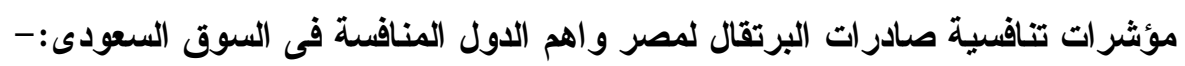

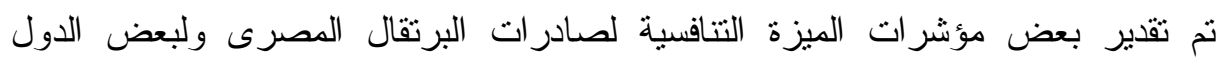
المنافسة داخل السوق السعودى خلال الفترتين (2009-2005)، (2014-2010) وفيما يلي

يتضح من الجدول رقم (4) أنه بتقدير النسبة السعرية خلال الفترة الاولى لمصر وبعض الدول المنافسة خلال الفترة (2009-2005) أن مصر لها ميزة نسبية سعرية عن كل من أسبانيا،

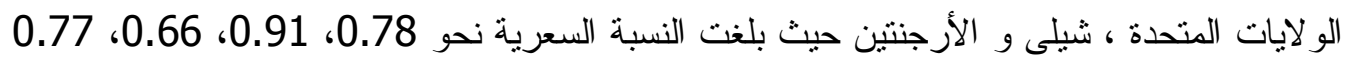

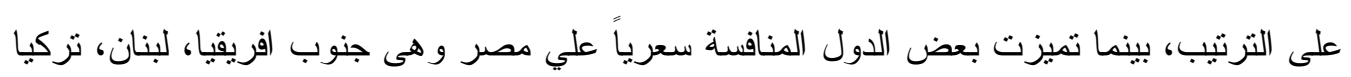

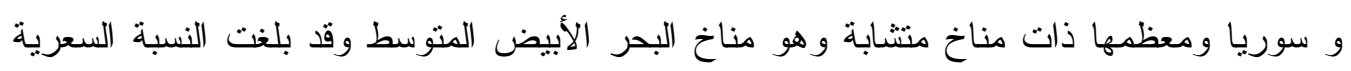

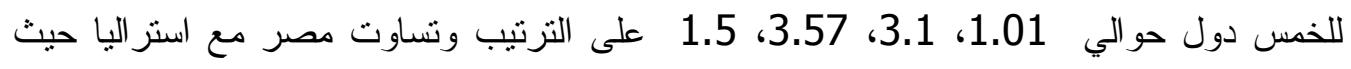
بلغت النسب السعرية الواحد الصحيح. بينما فى الفترة الثاية تقوقت مصر سعرياً عن كل من جنوب افريقيا، اسبانيا، الولايات

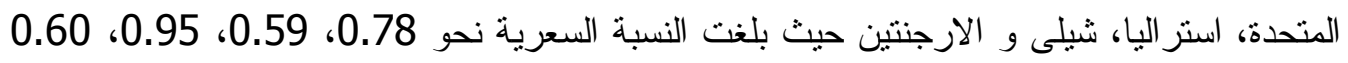

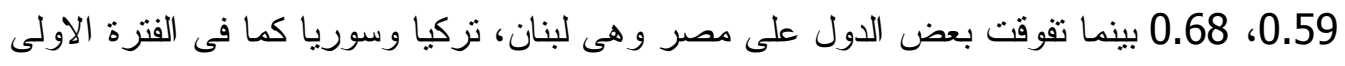

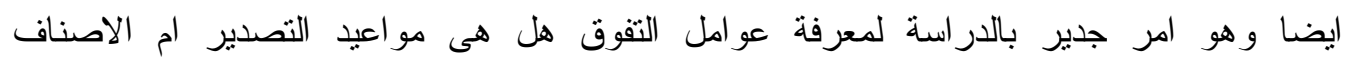
التصديرية او تكاليف التحويل المكانى وقد بلغت النسبة السعرية لهذة الدول نحو 1.28 فى الفترة الثانية. النصيب السوقى يتضح من الجدول رقم (4) أن مصر تميزت فى النصيب السوقى على جميع الدول

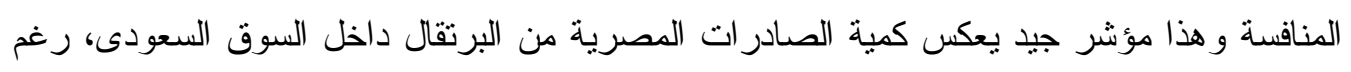

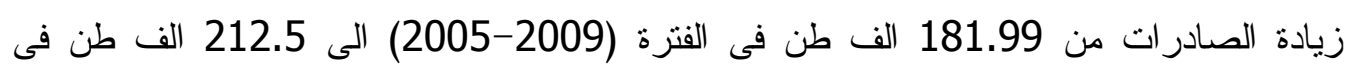
الفترة (2014-2010) حيث بلغ النصيب السوقى لكل من مصر، جنوب الفريقيا ولبنان فى الفترة

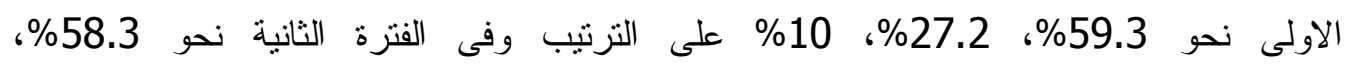

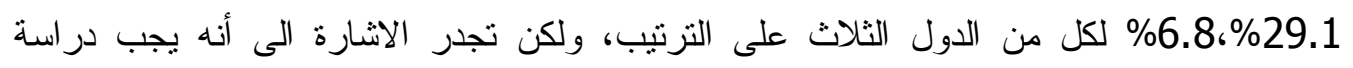

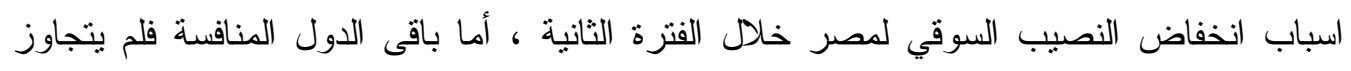

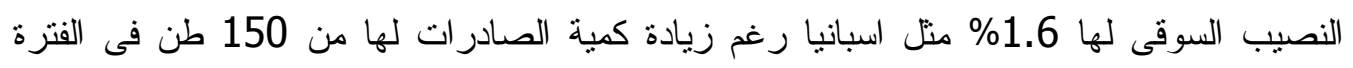
الاولى الى 5480 طن خلال الفترة الثانية. 


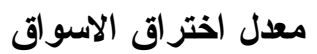

يتضح من الجدول رقم (5) ان معدل اختراق البرتقال المصرى للسوق السعودى يتفوق

على باقى الدول المنافسة خلا فترنى الدر اسة حيث بلغ هذا المعدل نحو 0.60، 0.28، 0.10 لكل من مصر، جنوب افريقيا ولبنان خلال الفترة الأولي على الترتيب، كما بلغ منوسط هذا المعدل حوالي 0.60 0.30، 0.07 خلال الفترة الثانية لهذة الدول الثناث على الترتيب ويكاد يكون معدل اختر اق صادرات البرتقال المصرى للسوق السعودى ثابتاً لكنه ارتفع عام 2014 الى 0.65 مما يعكس تفضيل المستهلك السعودى للبرتقال المصرى.

جدول رقم (4): النصيب السوقي والنسبة السعرية لأهم الدول المصدرة داخل السوق السعودي

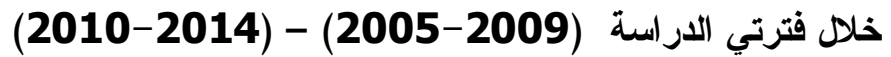

القيمة بالألف دولار أمريكي - الكمية بالأف طن

\begin{tabular}{|c|c|c|c|c|c|c|c|c|c|c|}
\hline اللفترة النسبة & اللنعبة اللنبة & سلفترة الثانية & اللفترة & اللفترة النصبي & اللنتوة النصيب & القيمة للفترة & اللفترة & اللفترة & اللفترة & الدول \\
\hline 1.00 & 1.00 & 496 & 511 & 58.32 & 59.29 & 105.28 & 212.47 & 92.93 & 181.99 & مصر \\
\hline 0.78 & 1.01 & 637 & 504 & 29.34 & 27.20 & 68.11 & 106.88 & 42.10 & 83.50 & افريقيا \\
\hline 2.39 & 3.10 & 207 & 165 & 6.83 & 10.02 & 5.15 & 24.87 & 5.06 & 30.76 & لبنان \\
\hline 0.59 & 0.78 & 845 & 658 & 1.50 & 0.05 & 4.63 & 5.48 & 0.10 & 0.15 & اسبانيا \\
\hline 0.95 & 0.91 & 522 & 562 & 0.88 & 0.03 & 1.68 & 3.22 & 0.04 & 0.08 & امريكا \\
\hline 0.60 & 1.00 & 824 & 509 & 0.53 & 0.37 & 1.60 & 1.95 & 0.58 & 1.13 & استر اليا \\
\hline 0.59 & 0.66 & 835 & 773 & 0.40 & 0.05 & 1.23 & 1.47 & 0.13 & 0.17 & شيلي \\
\hline 1.70 & 3.57 & 292 & 143 & 0.36 & 0.24 & 0.38 & 1.32 & 0.10 & 0.72 & تركيا \\
\hline 1.28 & 1.51 & 386 & 337 & 0.35 & 0.64 & 0.49 & 1.26 & 0.66 & 1.96 & سوريا \\
\hline 0.68 & 0.77 & 728 & 664 & 0.30 & 0.17 & 0.80 & 1.10 & 0.35 & 0.53 & الأرجنتين \\
\hline- & - & - & - & 1.18 & 1.94 & 2.87 & 4.30 & 2.72 & 5.97 & اخري \\
\hline 0.94 & 1.08 & 527.6 & 471.7 & 100.0 & 100.0 & 192.2 & 364.3 & 144.8 & 307.0 & السوق \\
\hline
\end{tabular}

المصدر : جمعت وحببت من بيانات شبكة المعلومات الدولية، الأنترنت، (comtrade.un). 
جدول رقم ( 5 ) : معدل اختراق الأسواق و الإنتاج النسبي و الميزة النسبية الظاهرة لصادرات مصر من البرتقال وبعض الدول المنافسة داخل السوق السعودي خلال الفترتي ن ( 2009-2005 ) ، ( 2010 - 2014 ).

\begin{tabular}{|c|c|c|c|c|c|c|c|c|c|c|c|c|c|}
\hline المتوسط & 2014 & 2013 & 2012 & 2011 & 2010 & المتوسط & 2009 & 2008 & 2007 & 2006 & 2005 & المؤشر & الدولة ل \\
\hline 0.61 & 0.65 & 0.63 & 0.61 & 0.58 & 0.57 & 0.6 & 0.6 & 0.57 & 0.57 & 0.62 & 0.63 & معدل اختراق السوق & \multirow{6}{*}{ جنوب افريقيا } \\
\hline 3.80 & 3.92 & 3.84 & 4.08 & 3.7 & 3.48 & 3.2 & 3.5 & 3.07 & 3.13 & 3.21 & 3.07 & الإنتاج النسبي & \\
\hline 20.06 & 47.4 & 12.5 & 13.4 & 12.9 & 14.0 & 20.5 & 14.5 & 15.4 & 16.9 & 18.3 & 37.7 & الميزة النسبية الظاهرة & \\
\hline 0.30 & 0.29 & 0.31 & 0.29 & 0.29 & 0.33 & 0.28 & 0.29 & 0.31 & 0.27 & 0.28 & 0.23 & معدل اختر اق السوق & \\
\hline 2.19 & 2.21 & 2.2 & 2.36 & 2.14 & 2.05 & 2.07 & 2.02 & 2.19 & 2.15 & 2.02 & 1.97 & الإنتاج النسبي & \\
\hline 0.19 & 0.2 & 0.23 & 0.2 & 0.18 & 0.16 & 0.12 & 0.14 & 0.14 & 0.13 & 0.14 & 0.05 & الميزة النسبية الظاهرة & \\
\hline 0.07 & 0.07 & 0.04 & 0.07 & 0.08 & 0.08 & 0.1 & 0.1 & 0.1 & 0.13 & 0.07 & 0.11 & معدل اختراق السوق & \multirow{3}{*}{ ل لبنان } \\
\hline 0.19 & 0.21 & 0.22 & 0.17 & 0.16 & 0.19 & 0.33 & 0.26 & 0.33 & 0.35 & 0.35 & 0.37 & الإنتاج النسبي & \\
\hline 1.84 & 2.19 & 1.02 & 2.78 & 1.87 & 1.32 & 2.09 & 1.21 & 1.47 & 2.35 & 1.67 & 3.73 & الميزة النسبية الظاهرة & \\
\hline 0.02 & 0.02 & 0.022 & 0.018 & 0.014 & 0.006 & 0.001 & - & - & 0.001 & 0.001 & 0.0001 & معدل اختر اق السوق & \multirow{3}{*}{ اسبانيا } \\
\hline 4.27 & 4.23 & 4.25 & 4.3 & 4.04 & 4.51 & 4.39 & 3.94 & 4.9 & 4.18 & 5.14 & 3.76 & الإنتاج النسبي & \\
\hline 0.01 & 0.01 & 0.03 & 0.01 & 0.01 & 0.01 & 0.0003 & - & - & 0.001 & 0.0008 & 0.0003 & الميزة النسبية الظاهرة & \\
\hline 0.01 & 0.01 & 0.01 & 0.003 & 0.014 & 0.01 & 0.0004 & - & - & 0.001 & 0.001 & 0.0001 & معدل اختراق السوق & \multirow{3}{*}{ امريكا } \\
\hline 10.60 & 9.02 & 9.62 & 11.97 & 11.58 & 10.83 & 12.31 & 12.22 & 13.14 & 10.55 & 12.36 & 13.3 & الإنتاج النسبي & \\
\hline 0.08 & 0.06 & 0.07 & 0.02 & 0.11 & 0.13 & 0.118 & - & - & 0.09 & 0.1 & 0.4 & الميزة النسبية الظاهرة & \\
\hline
\end{tabular}


الإنتاج النسبي

اما فيما يخص النسبة الانتاجية فقد تقوقت كل من الولايات المتحدة الامريكية واسبانيا علي مصر خلال فترتي الدراسة، حيث بلغت هذه النسبة نحو 12.31، 4.39، 3.20 لكل من الو لايات المتحدة الامريكية ، اسبانيا ومصر على الترتيب كمتوسط خلال الفترة الاولى، كما بلغت نحو 10.60 ، 4.27، 3.80 لهذة الدول خلد الفترة الثانية على الترتيب مما يعنى ضعف الانتاج المصرى بالنسبة للانتاج العالمى. الميزة النسبية الظاهرة

تفوقت مصر على الدول المنافسة لها داخل السوق السعودي بالنسبة للميزة النسبية الظاهرة حيث بلغ هذا المعدل حوالي 20.5، 0.118، 0.12، 2.09 لكل من مصر، الولايات المتحدة الامريكية، جنوب افريقيا، لبنان كمتوسط الفترة (2009-2005)، كما بلغ هذا المعدل نحو 20.1،

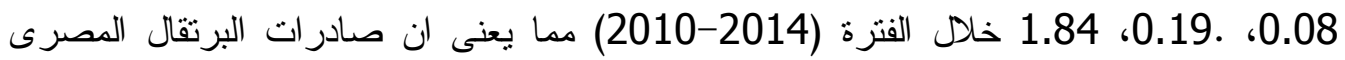

تحنل ميزة نسبية كبيرة بين الصادر ات الزر اعية و التى تسهم بدور ها بنسبة فى الصادر ات القومية. مؤشر ات تتافسية صادرات البرتقال لمصر وأهم الدول المنافسة فى السوق الروسي:حيث تم تقدير بعض مؤشرات الميزة النتافسية لصادرات البرتقال المصرى ولبعض الدول المنافسة داخل السوق الروسي خلال الفترتين (2009-2005)، (2014-2010) وفيما يلي النتائج:

النسبة السعرية يتضح من الجدول رقم (6) ان النسبة السعرية لصادرات البرنقال المصرى في السوق الروسى

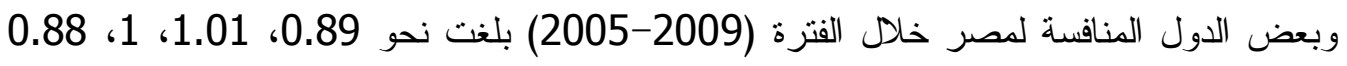
0.78 لكل من جنوب افريقيا، تركيا، المغرب، اسبانيا، الصين، أى أن مصر لها ميزة نسبية سعرية

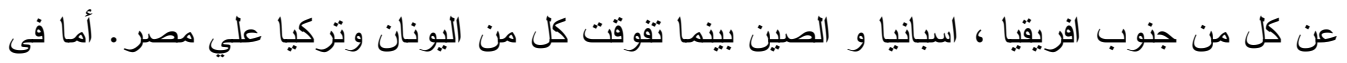

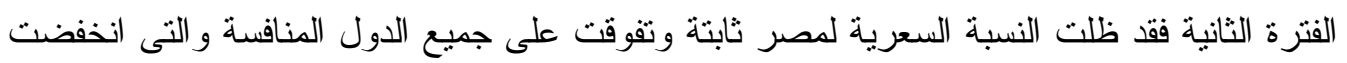
نسبتها السعرية النسبية عن الواحد الصحيح فيما عدا تركيا تساوت معها في النسبة السعرية وهو ما فئس بمكن إرجاعة إلي انخفاض قيمة الجنيه امام الدو لار . النصيب السوقى يتضح من الجدول رقم (6) ان مصر جاءت فى المرتبة الثانية من حيث النصيب السوقى

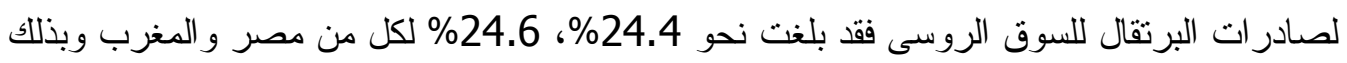
فإن المغرب قد احتلت المرتبة الأولي من حيث النصيب السوقي في السوق الروسي خلاد الفترة

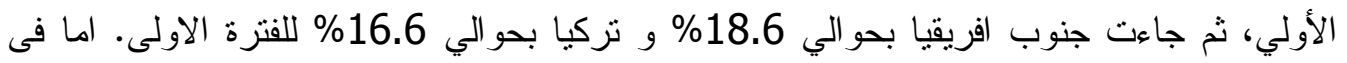

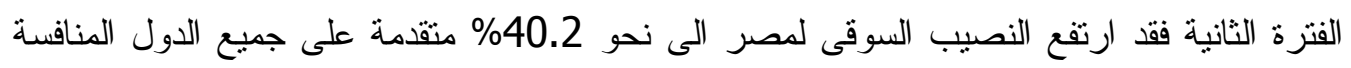




جدول رقم (6): النصيب السوقي والنسبة السعرية لأهم الدول المصدرة داخل السوق الروسي خلا فترتي الدراسة (2009-2005) - (2014-2010)

القيمة بالألف دولار أمريكي - الكمية بالأف طن

\begin{tabular}{|c|c|c|c|c|c|c|c|c|c|c|}
\hline اللنقالنقرة النسبة & اللستبة اللنسبة & للفعر الثنرة & سعر اللفنرة & اللنصيب النترة & اللنقيب اللفرة & للفنترة القيمة & اللفترة الكمية & اللقترة & اللفترة & الدول \\
\hline 1.00 & 1.00 & 876 & 628 & 40.20 & 24.4 & 177.0 & 202.0 & 71.8 & 114.2 & مصر \\
\hline 0.96 & 0.89 & 911 & 706 & 24.53 & 18.6 & 112.3 & 123.3 & 61.5 & 87.1 & جنوب افريقيا \\
\hline 1.00 & 1.01 & 877 & 623 & 15.61 & 16.6 & 68.8 & 78.4 & 48.4 & 77.8 & تركيا \\
\hline 0.95 & 1.00 & 921 & 628 & 9.35 & 24.6 & 43.3 & 47.0 & 72.1 & 114.8 & المغرب \\
\hline 0.81 & 0.88 & 1076 & 710 & 4.29 & 1.3 & 23.2 & 21.6 & 4.4 & 6.3 & اسبانيا \\
\hline 0.89 & 0.78 & 981 & 803 & 2.15 & 1.7 & 10.6 & 10.8 & 6.3 & 7.8 & الصين \\
\hline 0.98 & 1.00 & 897 & 626 & 1.79 & 9.0 & 8.1 & 9.0 & 26.4 & 42.1 & الأرجنتين \\
\hline 0.97 & 1.00 & 902 & 631 & 0.76 & 1.9 & 3.5 & 3.8 & 5.7 & 9.1 & اورجو اي \\
\hline 0.86 & 1.10 & 1014 & 570 & 0.30 & 0.2 & 1.6 & 1.5 & 0.5 & 0.9 & اليونان \\
\hline - & - & - & - & 1.02 & 1.6 & 7.4 & 5.1 & 8.4 & 7.5 & اخري \\
\hline 0.97 & 0.96 & 907 & 654 & 100.00 & 100.0 & 455.6 & 502.6 & 305.5 & 467.5 & اجمالي السوق \\
\hline
\end{tabular}

المصدر : جمعت وحسبت من بيانات شبكة المعلومات الدولية، الأنترنت، (comtrade.un). 
معدل اختراق الاسواق

يتضح من الجدول رقم (7) تفوق مصر خلال فترتي الدراسة بالنسبة لمعدل اختراق

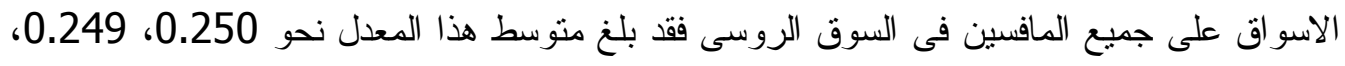

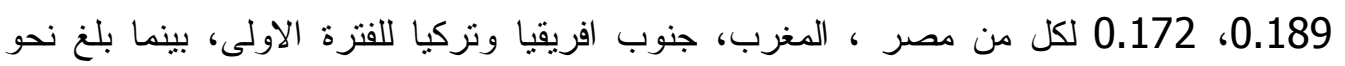

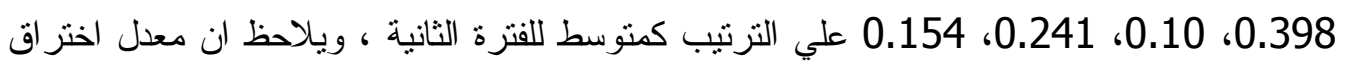

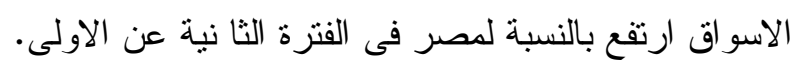
الإنتاج النسبي

يتبين من الجدول رقم (7) أن مصر جاءت فى المرتبة الثالثة من حيث الإنتاج النسبى كمتوسط للفترتين بعد كل من الصين و اسبانيا فقد بلغت هذة النسبة نحو 3.2،

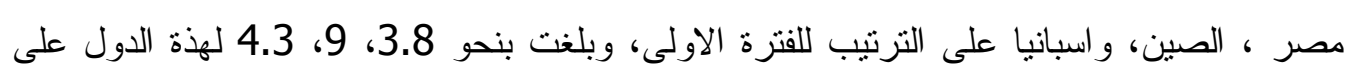
الترتيب خلال الفترة الثانية. الميزة النسبية الظاهرة

بإستقر اء بيانات الجدول رقم (7) يتضح أن مصر جاءت فى المرنبة الثانية بالنسبة للميزة

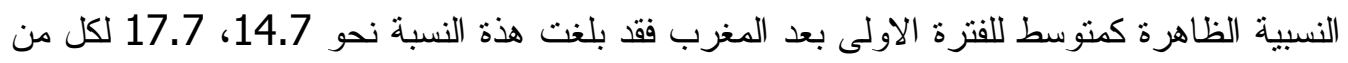

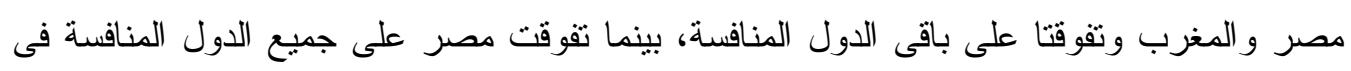
الفترة الثانية فقد بلغت هذة النسبة حوالي 34.8، 2.9، 0.3، وجنوب افريقيا كمنوسط الفترة الثاية على الترتيب.

مؤشرات تتافسية صادرات البرتقال لمصر واهم الدول المافسة فى السوق الاوكرانى:-

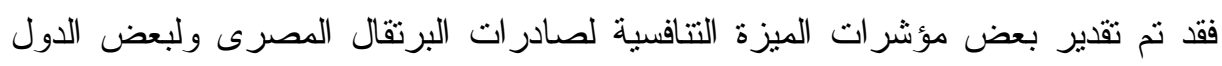
المنافسة داخل السوق الاوكراني خلا الفترتين (2009-2005)، (2014-2010) وفيما يلي

\section{النسبة السعرية}

تشير بيانات الجدول رقم (8) إلي أن النسبة السعرية لصادرات البرتقال المصرى في السوق الاوكر انى قد بلغت نحو 0.9، 0.76، 0.77، لكل من تركيا وجنوب افريقيا واسبانيا وهو أقل من الو احد الصحيح مما يدل على التميز السعرى للبرتقال المصرى فيى السوق الاوكرانى خلال



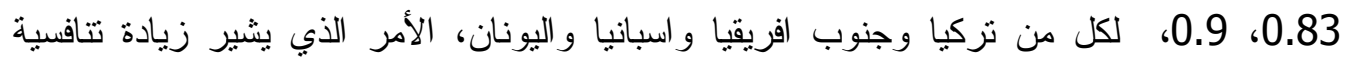

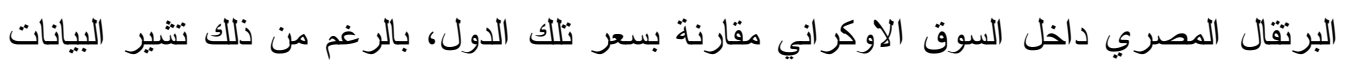

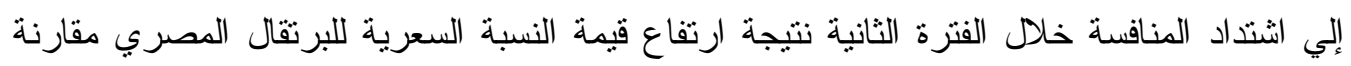
بالفترة الأولي للمنافسين. 
جدول رقم ( 7) : معدل اختراق الأسواق و الإنتاج النسبي والميزة النسبية الظاهرة لصادرات مصر من البرتقال وبعض الدول المنافسة داخل السوق الروسي

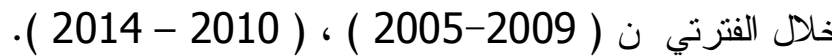

\begin{tabular}{|c|c|c|c|c|c|c|c|c|c|c|c|c|c|}
\hline المتوسط & 2014 & 2013 & 2012 & 2011 & 2010 & المتوسط & 2009 & 2008 & 2007 & 2006 & 2005 & 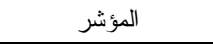 & الدولة الد \\
\hline 0.398 & 0.437 & 0.465 & 0.404 & 0.385 & 0.301 & 0.25 & 0.293 & 0.275 & 0.231 & 0.218 & 0.231 & معدل اختراق السوق & \multirow{3}{*}{ مصر } \\
\hline 3.8 & 3.9 & 3.8 & 4.1 & 3.7 & 3.5 & 2.8 & 2.8 & 3.0 & 2.9 & 2.8 & 2.5 & الإنتاج النسبي & \\
\hline 34.871 & 86.938 & 28.613 & 20.864 & 21.943 & 15.994 & 14.701 & 13.536 & 12.631 & 17.441 & 16.488 & 13.408 & الميزة النسبية الظاهرة & \\
\hline 0.241 & 0.243 & 0.256 & 0.242 & 0.202 & 0.264 & 0.189 & 0.214 & 0.212 & 0.213 & 0.163 & 0.142 & معدل اختراق السوق & \multirow{3}{*}{ جنوب افريقيا } \\
\hline 2.2 & 2.2 & 2.2 & 2.4 & 2.1 & 2.0 & 2.1 & 1.8 & 2.4 & 2.1 & 2.2 & 1.8 & الإنتاج النسبي & \\
\hline 0.193 & 0.175 & 0.164 & 0.201 & 0.168 & 0.255 & 0.211 & 0.256 & 0.296 & 0.193 & 0.184 & 0.125 & الميزة النسبية الظاهرة & \\
\hline 0.154 & 0.16 & 0.132 & 0.143 & 0.18 & 0.154 & 0.172 & 0.195 & 0.111 & 0.137 & 0.202 & 0.214 & معدل اختراق السوق & \multirow{3}{*}{ تركيا } \\
\hline 2.5 & 2.6 & 2.5 & 2.4 & 2.5 & 2.5 & 2.0 & 2.0 & 2.1 & 2.0 & 2.1 & 1.7 & الإنتاج النسبي & \\
\hline 2.946 & 2.438 & 2.345 & 2.576 & 4.297 & 3.074 & 0.059 & 0.053 & 0.028 & 0.04 & 0.073 & 0.102 & الميزة النسبية الظاهرة & \\
\hline 0.1 & 0.098 & 0.049 & 0.104 & 0.123 & 0.128 & 0.249 & 0.185 & 0.286 & 0.292 & 0.251 & 0.23 & معدل اختر اق السوق & \multirow{3}{*}{ المغرب } \\
\hline 1.2 & 1.2 & 1.2 & 1.4 & 1.2 & 1.2 & 1.2 & 1.1 & 1.4 & 1.2 & 1.2 & 1.4 & الإنتاج النسبي & \\
\hline 0.10 & 0.10 & 0.05 & 0.11 & 0.11 & 0.13 & 17.77 & 11.06 & 26.70 & 24.75 & 13.80 & 12.52 & الميزة النسبية الظاهرة & \\
\hline 0.045 & 0.05 & 0.055 & 0.051 & 0.039 & 0.03 & 0.013 & 0.014 & 0.021 & 0.016 & 0.009 & 0.008 & معدل اختراق السوق & \multirow{3}{*}{ اسبانيا } \\
\hline 4.3 & 4.2 & 4.3 & 4.3 & 4.0 & 4.5 & 4.6 & 4.3 & 5.1 & 4.8 & 4.8 & 4.1 & الإنتاج النسبي & \\
\hline 0.305 & 0.294 & 0.638 & 0.298 & 0.168 & 0.128 & 0.026 & 0.039 & 0.035 & 0.024 & 0.017 & 0.015 & الميزة النسبية الظاهرة & \\
\hline 0.024 & 0.023 & 0.019 & 0.029 & 0.018 & 0.031 & 0.017 & 0.03 & 0.019 & 0.015 & 0.011 & 0.01 & معدل اختراق السوق & \multirow{3}{*}{ الصين } \\
\hline 9.0 & 9.8 & 9.2 & 9.5 & 8.4 & 7.8 & 2.5 & 3.3 & 3.0 & 2.4 & 2.2 & 1.7 & الإنتاج النسبي & \\
\hline 0.078 & 0.055 & 0.049 & 0.068 & 0.062 & 0.155 & 0.298 & 0.414 & 0.194 & 0.21 & 0.295 & 0.375 & الميزة النسبية الظاهرة & \\
\hline
\end{tabular}

المصدر : جمعت وحسبت من : بيانات شبكة المعلومات الدولية الأنترنت، (FAO.org - Comtrade.UN) 
النصيب السوقى

يتضح من الجدول رقم (8) أن مصر تفوقت فى النصيب السوقى خلال الفترنين على كل

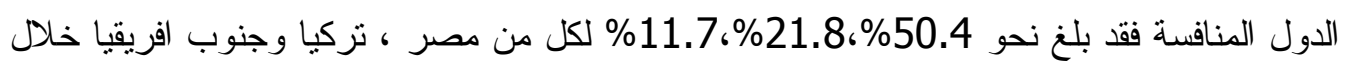

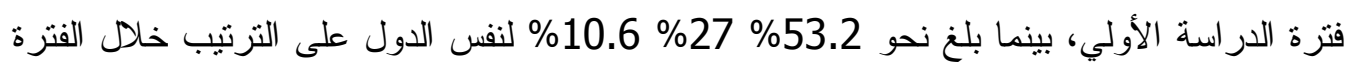

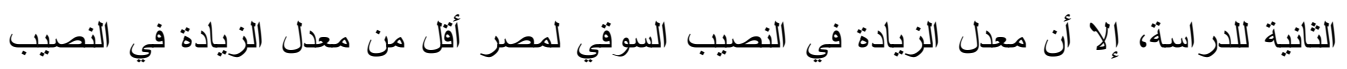
السوفي لتركيا، الأمر الذي يمكن إرجاعه إلي إثنتداد المنافسة السعرية خلال الفترة الثانية لنانية نتيجة تقارب النسبة السعرية لكل منهما خلال نلاك الفترة . معدل اختراق الاسواق

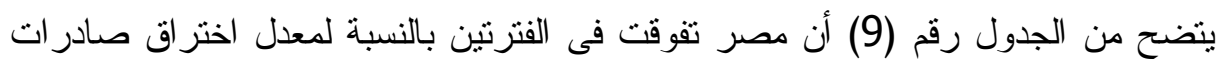
البرتقال المصرى للسوق الاوكر انى على جميع الدول المنافسة فقد بلغ نحو

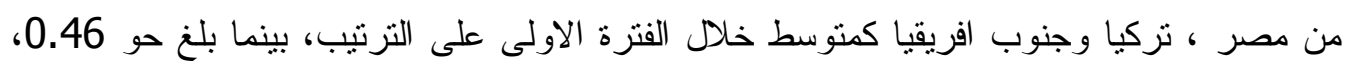
0.26، 0.10 لنفس الدول كمنوسط الفترة الثانية. الإنتاج النسبي

يتبين من الجدول رقم (9) أن مصر جاءت فى المركز الثانى بالنسبة للاول المنافسة داخل

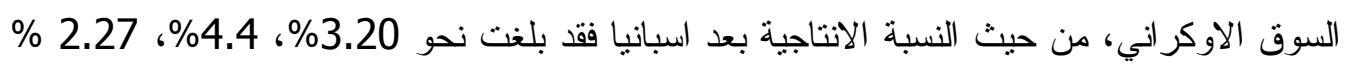

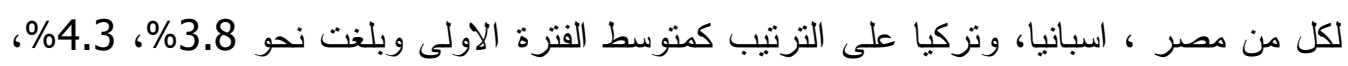
2.5 النفس الدول كمتوسط للفترة الثانية على الترتيب.

الميزة النسبية الظاهرة

يتضح من الجدول رقم (9) ان مصر تفوقت على جميع الدول المنافسة بالنسبة للميزة النسبية الظاهرة خلال فترتى الدر اسة فقد بلغت نحو 16.84، 2.96، و الارجنتين كمتوسط الفترة الاولى على الترتيب، بينما بلغت نحو 26.89، 1.72، مصر ،اليونان ونزكيا كمتوسط للفترة الثانية على النزتيب. ويتضح من دراسة مؤشرات النصبب السوقي ومعدل إختراق السوق و الميزة النسبي علئي الظاهرة للبرتقال المصري في كل من السوق الروسي و السوق الأوكراني أن الدول التي نتنمي إلي وني

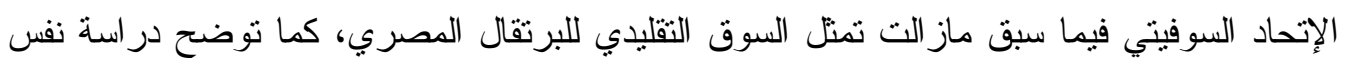
المؤشرات في السوق السعودي إلي أن هذا السوق يمثل السوق العربي التقليدي الأول للبرتقال

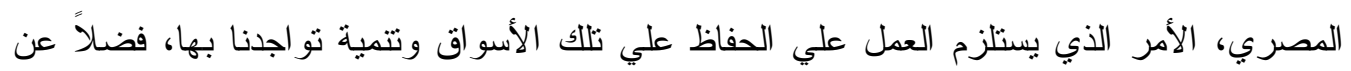



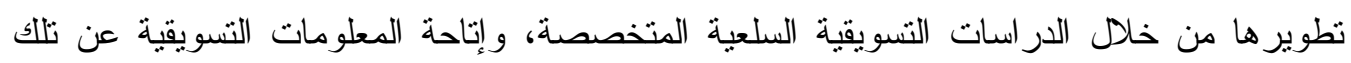
الأسواق، و الأهتمام بموصفات جودة البرتقال المصري بالإضافة إلي بذل مزيد من الجهد الترويجي ولئية بتلك الأسواق. 
جدول رقم (8): النصيب السوقي والنسبة السعرية لأهم الدول المصدرة داخل السوق الاوكر نان خلال فترتي الدراسة (2009-2005) - (2014- (2010)

القيمة بالألف دولار أمريكي - الكمية بالأف طن

\begin{tabular}{|c|c|c|c|c|c|c|c|c|c|c|}
\hline اللفال النقرية & اللالنترة اللنسبة & اللفنر & الطعر اللفترة & النصيب اللفوقي & اللصيب اللفترة & اللفترة & اللفترة الكمية & اللقترة & اللفترة & الدول \\
\hline 1 & 1 & 833 & 339 & 53.24 & 50.4 & 54.49 & 65.41 & 22.83 & 67.27 & مصر \\
\hline 0.98 & 0.90 & 849 & 376 & 27.00 & 21.8 & 28.15 & 33.18 & 10.97 & 29.14 & تركيا \\
\hline 0.89 & 0.76 & 936 & 448 & 10.61 & 11.7 & 12.20 & 13.04 & 6.99 & 15.60 & جنوب افريقيا \\
\hline 0.83 & 0.77 & 1006 & 438 & 6.27 & 3.8 & 7.74 & 7.70 & 2.21 & 5.04 & اسبانيا \\
\hline 0.90 & 1.03 & 925 & 330 & 1.09 & 1.6 & 1.24 & 1.34 & 0.70 & 2.13 & اليونان \\
\hline 1.07 & 0.96 & 778 & 354 & 0.35 & 4.8 & 0.33 & 0.43 & 2.28 & 6.45 & الأرجنتين \\
\hline 0.89 & 1.12 & 937 & 304 & 0.20 & 3.9 & 0.23 & 0.25 & 1.57 & 5.18 & قبرص \\
\hline 0.86 & 0.47 & 972 & 722 & 0.41 & 0.2 & 0.49 & 0.50 & 0.21 & 0.29 & زيمبابوي \\
\hline 0.99 & 0.75 & 842 & 453 & 0.35 & 0.2 & 0.36 & 0.43 & 0.15 & 0.33 & ايطاليا \\
\hline 0.74 & 1.14 & 1122 & 299 & 0.05 & 0.9 & 0.07 & 0.06 & 0.36 & 1.19 & اسر ائيل \\
\hline 0.90 & 0.81 & 928 & 420 & 0.43 & 0.7 & 0.49 & 0.53 & 0.37 & 0.88 & اخري \\
\hline 0.97 & 0.93 & 861 & 364 & 100.00 & 100.0 & 105.80 & 122.86 & 48.64 & 133.50 & اجمالي السوق \\
\hline
\end{tabular}

المصدر : جمعت وحسبت من: بيانات شبكة المعلومات الدولية، الأنترنت، (comtrade.un). 
جدول رقم ( 9 ) : معدل اختراق الأسواق والنسبة الإنتاجية والميزة النسبية الظاهرة لصادرات مصر من البرتقال وبعض الدول المنافسة داخل السوق الأوكراني

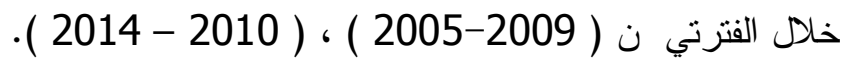

\begin{tabular}{|c|c|c|c|c|c|c|c|c|c|c|c|c|c|}
\hline المتوسط & 2014 & 2013 & 2012 & 2011 & 2010 & المتوسط & 2009 & 2008 & 2007 & 2006 & 2005 & المؤشر & الدولة \\
\hline 0.47 & 0.62 & 0.28 & 0.68 & 0.41 & 0.37 & 0.23 & 0.40 & 0.26 & 0.24 & 0.12 & 0.13 & معدل اختراق السوق & \multirow{3}{*}{ مصر } \\
\hline 3.8 & 3.92 & 3.84 & 4.08 & 3.7 & 3.48 & 3.2 & 3.5 & 3.07 & 3.13 & 3.21 & 3.07 & الإنتاج النسبي & \\
\hline 26.89 & 102.06 & 4.96 & 9.48 & 7.98 & 9.97 & 16.84 & 8.48 & 10.12 & 22.84 & 23.35 & 19.43 & الميزة النسبية الظاهرة & \\
\hline 0.26 & 0.35 & 0.25 & 0.34 & 0.18 & 0.17 & 0.10 & 0.16 & 0.17 & 0.07 & 0.04 & 0.06 & معدل اختراق السوق & \multirow{3}{*}{ تركيا } \\
\hline 2.51 & 2.59 & 2.55 & 2.44 & 2.48 & 2.48 & 2.27 & 2.49 & 2.05 & 2.18 & 2.33 & 2.29 & الإنتاج النسبي & \\
\hline 0.11 & 0.08 & 0.17 & 0.1 & 0.09 & 0.11 & 0.07 & 0.1 & 0.1 & 0.03 & 0.05 & 0.08 & الميزة النسبية الظاهرة & \\
\hline 0.10 & 0.13 & 0.10 & 0.07 & 0.10 & 0.08 & 0.07 & 0.12 & 0.08 & 0.08 & 0.03 & 0.04 & معدل اختراق السوق & \multirow{3}{*}{ جنوب افريقيا } \\
\hline 2.19 & 2.21 & 2.2 & 2.36 & 2.14 & 2.05 & 2.07 & 2.02 & 2.19 & 2.15 & 2.02 & 1.97 & الإنتاج النسبي & \\
\hline 0.57 & 0.79 & 0.6 & 0.34 & 0.62 & 0.5 & 0.81 & 0.78 & 0.62 & 1.06 & 0.86 & 0.75 & الميزة النسبية الظاهرة & \\
\hline 0.07 & 0.10 & 0.05 & 0.10 & 0.06 & 0.05 & 0.02 & 0.04 & 0.02 & 0.02 & 0.02 & 0.02 & معدل اختراق السوق & \multirow{3}{*}{ اسبانيا } \\
\hline 4.27 & 4.23 & 4.25 & 4.3 & 4.04 & 4.51 & 4.39 & 3.94 & 4.9 & 4.18 & 5.14 & 3.76 & الإنتاج النسبي & \\
\hline 0.23 & 0.13 & 0.14 & 0.44 & 0.24 & 0.18 & 0.11 & 0.12 & 0.09 & 0.12 & 0.11 & 0.09 & الميزة النسبية الظاهرة & \\
\hline 0.01 & 0.01 & 0.01 & 0.01 & 0.01 & 0.01 & 0.01 & 0.01 & 0.01 & 0.002 & 0.002 & 0.01 & معدل اختراق السوق & \multirow{3}{*}{ اليونان } \\
\hline 1.18 & 1.06 & 1.1 & 1.16 & 1.28 & 1.31 & 1.3 & 1.25 & 1.15 & 1.24 & 1.36 & 1.48 & الإنتاج النسبي & \\
\hline 1.72 & 2.4 & 0.97 & 0.53 & 1.98 & 2.73 & 2.96 & 1.74 & 2.28 & 1.32 & 1.47 & 7.97 & الميزة النسبية الظاهرة & \\
\hline 0.002 & 0.001 & 0.000 & 0.001 & 0.001 & 0.004 & 0.02 & 0.01 & 0.01 & 0.02 & 0.02 & 0.02 & معدل اختراق السوق & \multirow{3}{*}{ الأرجنتين } \\
\hline 1.27 & 1.29 & 1.29 & 1.32 & 1.26 & 1.21 & 1.36 & 1.33 & 1.36 & 1.22 & 1.5 & 1.4 & الإنتاج النسبي & \\
\hline 0.26 & 1 & 0.04 & 0.06 & 0.04 & 0.16 & 2.09 & 0.35 & 1.09 & 2.71 & 5.27 & 1.02 & الميزة النسبية الظاهرة & \\
\hline
\end{tabular}

المصدر : جمعت وحسبت من : بيانات شبكة المعلومات الدولية الأنترنت، (FAO.org - Comtrade.UN) 


\section{النافذة الموسمية لاخول السوق:-}

تم في هذا الصدد مقارنة اوقات الدخول الموسمي الثهري لصادرات البرتقال المصري مع الطلب الموسمي الثهري لكمية واردات كل من السوق السعودي و الروسي فقط، حيث تعذر الحصول علي بيانات الواردات الثهرية للسوق الاوكر اني، ونتشير بيانات الجدول رقم (10) إلي أن الصادر ات المصرية الثهرية من البرتقال إلي السوق السعودي خلال الفترة ( 2012 - 2014 ) تتركز خلال الفترة من يناير إلي مايو حيث بلغت أعلاها في شهر فبر اير بمتوسط كمية بلغت نحو 45.6 ألف طن بما يمثل نحو 92.8\% من كمية واردات السوق السعودي خلال هذا الشهر المقدرة بحوالي 49.2 ألف طن، كذللك تركزت الواردات الثهرية للسوق السعودي خلال الفترة من ديسمبر إلي ابريل، حيث

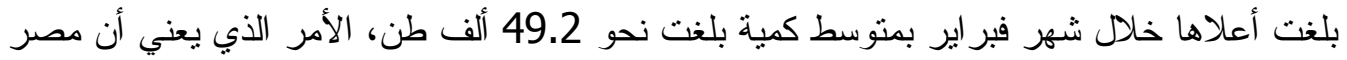



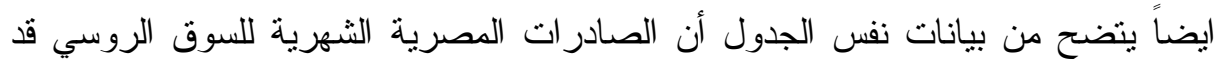
بلغت في المتوسط حو الي 16.8 ألف طن، حيث تركزت خلال الفترة من يناير إلي مايو حيث بلغت

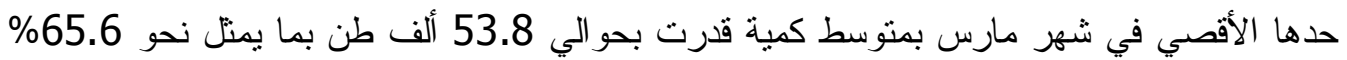

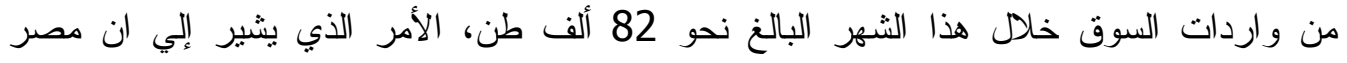
تستحوذ علي النصيب الأكبر داخل السوق الروسي، كذللك يتبين أن واردات السوق الروسي تتركز خلال الفترة من نوفمبر إلي ابريل بحد أقصي خلال شهر مارس البالغ نحو 82 ألف طن. جدول رقم (10): النافذة التصديرية و الأستير ادية الثهرية للبرنقال المصري داخل كل من السوق السعودي و الروسي خلال متوسط الفترة ( 2014-2012)



\begin{tabular}{|c|c|c|c|c|c|c|c|c|}
\hline \multicolumn{3}{|c|}{ السوق الروسي } & \multirow{2}{*}{ مصر } & \multicolumn{2}{|c|}{ السوق السعودي } & \multicolumn{2}{|c|}{ مصر } & \multirow[b]{2}{*}{ الشهر } \\
\hline الموسمي & الكمية & الموسمي & & الدليل الموسمي & الكمية & الدليل الموسمي & الكمية & \\
\hline 111.2 & 46845 & 151.2 & 25459 & 124 & 39353 & 191 & 36426 & يناير \\
\hline 153.8 & 64802 & 216.8 & 36493 & 155 & 49168 & 240 & 45657 & فبر اير \\
\hline 194.6 & 81984 & 319.5 & 53793 & 129 & 40945 & 199 & 37853 & مارس \\
\hline 121.3 & 51119 & 205.5 & 34604 & 102 & 32477 & 138 & 26247 & ابريل \\
\hline 85.7 & 36104 & 150.5 & 25334 & 97 & 30910 & 124 & 23611 & مايو \\
\hline 60.5 & 25507 & 63.1 & 10631 & 79 & 24898 & 63 & 11952 & يونيو \\
\hline 46.1 & 19422 & 5.0 & 839 & 92 & 29081 & 28 & 5252 & يوليو \\
\hline 40.5 & 17078 & 0.5 & 89 & 74 & 23527 & 3 & 542 & اغسطس \\
\hline 54.4 & 22919 & 0.0 & 1 & 81 & 25836 & 0 & 0 & سبتمبر \\
\hline 87.2 & 36723 & 0.0 & 0 & 92 & 29300 & 6 & 1143 & اكتوبر \\
\hline 106.8 & 44992 & 0.0 & 0 & 70 & 22072 & 52 & 9943 & نوفمبر \\
\hline 137.9 & 58084 & 87.9 & 14793 & 104 & 33010 & 157 & 29819 & ديسمبر \\
\hline 100.0 & 42132 & 100.0 & 16836 & 100 & 31715 & 100 & 19037 & المتوسط \\
\hline
\end{tabular}

المصدر : جمعت وحسبت من: بيانات شبكة المعلومات الدولية، الأنترنت، (comtrade.un). 


\section{التوصيات}

1. توسيع السوق الخارجي للبرتقال حيث يتسم بالتركز الجغر افي في السوق العالمي الامر

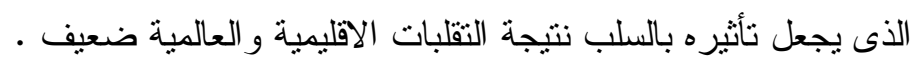

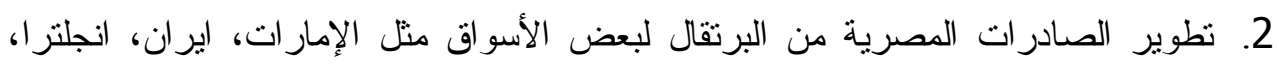

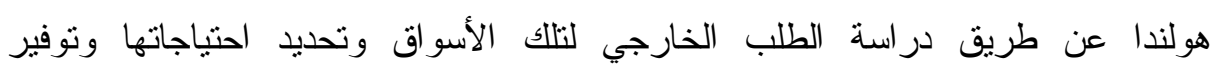

المعلومات التسويقية للمصدرين إلي تلك الأسواق عن المستوردين فيها.

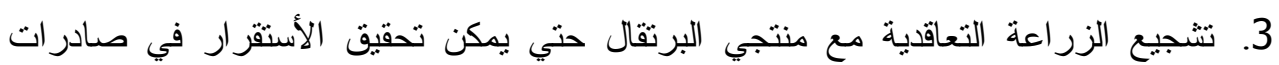

البرنقال المصري.

المراجع

مر اجع باللغة العربية

1. اسماء احمد محمود ( دكتورة ) " صادر بات البرتقال المصري في ظل المتغير ات الاقتصادية

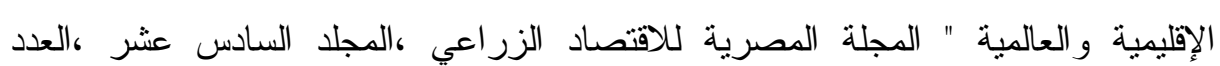

السادس،سبتمبر 2006.

2. فوزي عبدالعزيز الثاذلي (دكتور) وأخرون، " الأداء السوقي التصديري للحاصلات

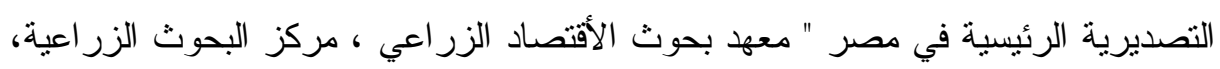

مايو 2009 . 2009

3. الجهاز المركزي للتعبئة العامة والإحصاء، شبكة المعلومات الدولية، الإنترنت.

4. الأمم المتحدة للتجارة العالمية، شبكة المعلومات الدولية، الإنترنت.

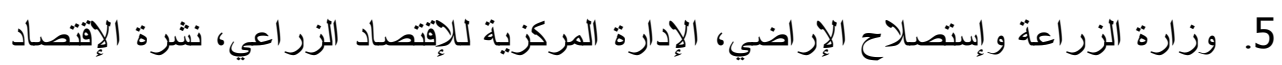

الزر اعي، أعداد مختلفة.

مر اجع باللغة الإنجليزية

1. FAO . Org. Internet.

2. Michael Porter "The Competitive Advantage of Nations" New York, Free Press, 1995.

3. Ashraf Kamal Abbas, "The Competitiveness of the Main Egyptian Agricultural Exports (1991 - 1994) and (1995-1998), Egyptian Journal of Applied Science Vol. (15) No (7) July 2000. 